\title{
Vitreous Amyloidosis as the Presenting Symptom of Familial Amyloid Polyneuropathy TTR Val30Met in a Portuguese Patient
}

\author{
Mariana Seca ${ }^{a}$ Natália Ferreira ${ }^{a}$ Teresa Coelho ${ }^{b, c}$ \\ ${ }^{a}$ Ophthalmology Department, ${ }^{\mathrm{b}}$ Familial Amyloid Polyneuropathy Clinical Unit, and \\ ${ }^{\mathrm{C} N e u r o p h y s i o l o g y}$ Department, Hospital Santo António, Centro Hospitalar do Porto, \\ Porto, Portugal
}

\section{Key Words}

Familial amyloid polyneuropathy · Transthyretin · Vitreous amyloidosis

\begin{abstract}
Familial amyloid polyneuropathy (FAP) is a group of disorders characterized by the extracellular deposition of amyloid substance in various tissues. The peripheral nervous system and the heart are the main target organs, but the eye may also be involved. We report a case of vitreous amyloidosis as the first manifestation of FAP in a 66-year-old Portuguese man without a family history.

(c) 2014 S. Karger AG, Basel
\end{abstract}

\section{Introduction}

Familial amyloid polyneuropathy (FAP) is an inherited disorder with autosomal dominant transmission, characterized by systemic extracellular accumulation of amyloid fibrils [1]. The most common type of FAP is related to transthyretin (TTR), a protein that carries thyroxine and vitamin A [2]. Plasma-circulating TTR is mainly synthesized in the liver, but there is also production in the retinal pigment epithelium and in the choroid plexus $[3,4]$. The clinical expression is variable among different mutations and different populations, and even the same population with the same mutation can present significant variability. The age of onset varies between the $20 \mathrm{~s}$ and the $90 \mathrm{~s}$. The peripheral nerves and the heart are the organs most frequently affected [5].

More than 100 mutations have been related to FAP, but one point mutation in which a methionine residue replaces the valine residue at position 30 (TTR Val30Met) is particularly 
frequent and is associated with several large foci around the world, namely Portugal, Japan, Sweden and the Balearic Islands [6-9]. This condition was first described in Portugal in 1952, when Andrade [10] reported a peculiar neuropathy characterized by ascending sensory-motor loss and severe autonomic dysfunction, affecting patients of both genders between 25 and 35 years of age.

Vitreous involvement was mentioned for the first time by Kantarjian and DeJong [11] in 1953 in two siblings with FAP. The first description of the Swedish focus in 1968 also reported the occurrence of vitreous opacities along with the typical sensory, motor and autonomic neuropathy with onset at a later age if compared with Portuguese and Japanese patients [12]. In Portugal, vitreous opacities have rarely been described in patients with the natural and fatal course of the disease [13], but the prolonged survival after liver transplant led to a significant increase in the prevalence of this problem $[14,15]$.

Ocular manifestations of FAP include abnormal conjunctival vessels, keratoconjunctivitis sicca, irregularities on lens surface and border of the pupil, change of pupillary shape and light reflex, vitreous opacities and glaucoma [16, 17]. Vitreous deposits of amyloid may be seen as one manifestation among other signs of the disease, but it has also been described as the earliest, isolated symptom of the disease [18-20].

We report a case of vitreous opacities as the initial manifestation of FAP TTR Val30Met in a late-onset Portuguese patient without a history of FAP.

\section{Case Report}

An apparently healthy 66-year-old man, born in Santa Maria da Feira and resident in Vila Nova de Gaia, Portugal, was first examined in March 2010 for right blurred vision and floaters. Symptoms were progressing for 2 months. Best-corrected visual acuity was 20/30 in the right eye and 20/20 in the left eye. The anterior segment of both eyes was unremarkable, with no abnormal conjunctival vessels, no change of pupillary shape, and no amyloid deposition at pupillary border or lens surface. Intraocular pressure, ocular movements and pupillary reflexes were normal. Vitreous yellowish-white opacities precluding examination of the fundus were identified in the right eye. The vitreous and retina of the left eye were normal.

Full clinical evaluation showed an asymptomatic first-degree atrioventricular (AV) block in the absence of other neurologic or cardiac signs of disease. The mutation TTR Val30Met was identified by full sequencing of the gene, and a salivary gland biopsy was done but failed to show amyloid deposition.

In November 2010, as the right visual acuity dropped to 20/100 the patient underwent a pars plana vitrectomy. The pathological examination of the surgical specimen which included Congo red stain showed material with yellowish-green birefringence consistent with amyloid. Postoperatively, best-corrected visual acuity was 20/20. In the summer of 2011, the patient had several episodes of dizziness and fainting. A Mobitz 2 second-degree AV block was demonstrated with a Holter register and he was submitted to a pacemaker implantation, with complete recovery of these symptoms. In September 2012, the visual acuity decreased to 20/100 in both eyes. The right eye developed a cataract and the left eye presented vitreous opacities (fig. 1). At that time, the light pupillary reflex and the pupil shape were normal. Biomicroscopy of both eyes revealed no amyloid deposits on the lens surface or at the pupillary border. The intraocular pressure was normal. He was submitted to a phacoemulsification of the cataract with intraocular lens implantation in the right eye in September 2012. One month later, pars plana vitrectomy was performed in the left eye 
without complications (fig. 2). In February 2013, his best-correct visual acuity of both eyes was $20 / 20$, and the ophthalmological examination was normal, except for pseudophakia of the right eye.

The patient remains free of neurologic symptoms or signs. There is no evidence of FAP in any of the patient's relatives. His parents died very old without FAP manifestations. Nine siblings ( 1 brother, 1 sister and 7 half-brothers and half-sisters), 3 sons and 7 grandsons had no symptoms suggesting onset of the disease up to the time of reporting (fig. 3 ).

\section{Discussion}

FAP is a heterogeneous disease characterized by systemic accumulation of mutant amyloidogenic TTR in different tissues, including the eye. Portugal is the largest focus of the disease in the world, and it is related almost exclusively to the same mutation, TTR Val30Met. The age of onset shows a wide range (from 17 to 78 years), but $87 \%$ of patients developed symptoms before 40 years of age (mean 33.5 years of age) [6]. Nevertheless, our patient had a much later age of onset.

Ocular manifestations commonly reported in FAP patients are abnormal conjunctival vessels, keratoconjunctivitis sicca, pupillary abnormalities, glaucoma and vitreous opacity. In a study with 37 Japanese patients, abnormal conjunctival vessels had the highest incidence with $100 \%$ after 10 years of follow-up, followed by the other abnormalities, with vitreous opacities reaching $17 \%$ in the same follow-up. It was also demonstrated that ocular manifestations increase with time $[16,21]$. However, our patient had no other ocular manifestation except vitreous opacities, which are, when numerous, pathognomonic of the disease. In Portuguese FAP patients, vitreous opacities usually occur years after neurologic manifestations and are associated with other ocular changes, such as pupillary abnormalities.

Vitreous amyloid deposits are one of the main causes of decreased visual acuity in FAP patients. Although there are some reports describing isolated vitreous opacities, to the best of our knowledge, this is the first description of a similar case in a Portuguese patient. At least 20 mutations of TTR have been related to vitreous deposits, including TTR Val30Met, TTR Tyr114Cys, TTR Phe33Val, TTR Ile84Ser and TTR Ile84Asp [22]. In a report of Swedish homozygous Val30Met patients, all developed vitreous opacities [23]. In Portugal, the only mutation identified in patients with vitreous opacities was TTR Val30Met, as in our patient.

Ideally, treatment of vitreous amyloidosis should remove the existing amyloid fibrils and prevent further amyloid deposition. Vitrectomy, which can be diagnostic and therapeutic, is a safe and effective surgical treatment done when a significant visual morbidity is present [24]. Our patient improved to 20/20 visual acuity in both eyes after vitrectomy. The recurrence of vitreous opacities after vitrectomy has been described in some series [24, 25]. Beirão et al. [26] detected new amyloid deposits in all eyes submitted to nonextensive vitrectomy. This should be prevented with an extraction, as complete as possible, of vitreous, particularly behind the posterior capsule of lens. Koga et al. [24] suggest performing phacoemulsification and intraocular lens implantation because more extensive removal of the vitreous base is possible with lens removal. So far, our patient has had no recurrence.

It is known that TTR, the precursor protein of amyloid, is predominantly synthesized by the liver. Primarily, it has been suggested that amyloid deposits in the vitreous because TTR can cross the blood-aqueous barrier [27]. However, there is evidence of TTR synthesis in the retinal pigment epithelium of the eye [3], and it has been proposed that vitreous amyloid deposition is the result of the local synthesis of the mutated TTR [28]. In a study of Kawaji et 
al. [29] on rabbit eyes, it is suggested that ciliary pigment epithelium may also synthesize TTR in addition to the retinal pigment epithelium. The frequent occurrence of ocular amyloid deposition after liver transplantation confirms the importance of persistent local synthesis of mutated TTR [30].

Patients with the Val30Met mutation usually present sensory-dominant polyneuropathy (more commonly in lower limbs), autonomic disturbances and cardiac dysfunction. In the present case, an $\mathrm{AV}$ block needing a pacemaker implantation was the only systemic manifestation during the follow-up. This means the vitreous amyloid can be a signal of a potential severe systemic disease despite an absence of systemic manifestations, demonstrating the importance of being alert to the whole system. This unusual presentation should not preclude the diagnosis because vitreous opacities are pathognomonic of amyloidosis.

In conclusion, the ophthalmologist can have an important role as the first physician detecting typical manifestations of the disease. Ocular manifestations such as vitreous opacities and glaucoma lead to visual impairment and can potentially be addressed by surgery. An accurate and frequent follow-up evaluation is needed for the detection of ocular manifestations to ensure a good vision and quality of life of FAP patients.

\section{Declaration of Interest}

The authors report no conflicts of interest. They are responsible for the content and writing of the paper.

\section{References}

-1 Ando Y, Nakamura M, Araki S: Transthyretin-related familial amyloidotic polyneuropathy. Arch Neurol 2005;62:1057-1062.

-2 Benson MD, Kincaid JC: The molecular biology and clinical features of amyloid neuropathy. Muscle Nerve 2007;36:411-423.

-3 Cavallaro T, Martone RL, Dwork AJ, Schon EA, Herbert J: The retinal pigment epithelium is the unique site of transthyretin synthesis in the rat eye. Invest Ophthalmol Vis Sci 1990;31:497-501.

4 Herbert J, Wilcox JN, Pham KT, Fremeau RT Jr, Zeviani M, Dwork A, et al: Transthyretin: a choroid plexusspecific transport protein in human brain. Neurology 1986;36:900-911.

5 Planté-Bordeneuve V, Said G: Familial amyloid polyneuropathy. Lancet Neurol 2011;10:1086-1097.

6 Sousa A, Coelho T, Barros J, Sequeiros J: Genetic epidemiology of familial amyloidotic polyneuropathy (FAP)-type I in Póvoa do Varzim and Vila do Conde (north of Portugal). Am J Med Genet 1995;60:512-521.

-7 Ikeda S, Hanyu N, Hongo M, Yoshioka J, Oguchi H, Yanagisawa N, Kobayashi T, Tsukagoshi H, Ito N, Yokota T: Hereditary generalized amyloidosis with polyneuropathy. Clinicopathological study of 65 Japanese patients. Brain 1987;110:315-337.

-8 Holmgren G, Holmberg E, Lindström A, Lindström E, Nordenson I, Sandgren O, Steen L, Svensson B, Lundgren E, von Gabain A: Diagnosis of familial amyloidotic polyneuropathy in Sweden by RFLP analysis. Clin Genet 1988;33:176-180.

-9 Munar-Qués M, Saraiva MJ, Viader-Farré C, Zabay-Becerril JM, Mulet-Ferrer J: Genetic epidemiology of familial amyloid polyneuropathy in the Balearic Islands (Spain). Amyloid 2005;12:54-61.

10 Andrade C: A peculiar form of peripheral neuropathy; familiar atypical generalized amyloidosis with special involvement of the peripheral nerves. Brain 1952;75:408-427.

11 Kantarjian AD, DeJong RN: Familial primary amyloidosis with nervous system involvement. Neurology 1953;3:399-409.

12 Andersson R, Kassman T: Vitreous opacities in primary familial amyloidosis. Acta Ophthalmol (Copenh) 1968;46:441-447.

13 Monteiro JG, Martins AF, Figueira A, Saraiva MJ, Costa PP: Ocular changes in familial amyloidotic polyneuropathy with dense vitreous opacities. Eye 1991;5:99-105.

-14 Beirão NM, Matos ME, Menéres MJ, Beirão IM, Costa PP, Torres PA: Vitreous surgery impact in glaucoma development in liver transplanted familial amyloidosis ATTR V30M Portuguese patients. Amyloid 2012;19:145-151. 
Seca et al.: Vitreous Amyloidosis as the Presenting Symptom of Familial Amyloid Polyneuropathy TTR Val30Met in a Portuguese Patient

15 Hara R, Kawaji T, Ando E, Ohya Y, Ando Y, Tanihara H: Impact of liver transplantation on transthyretinrelated ocular amyloidosis in Japanese patients. Arch Ophthalmol 2010;128:206-210.

-16 Ando E, Ando Y, Okamura R, Uchino M, Ando M, Negi A: Ocular manifestations of familial amyloidotic polyneuropathy type I: long-term follow up. Br J Ophthalmol 1997;81:295-298.

17 Haraoka K, Ando Y, Ando E, Sandgren O, Hirata A, Nakamura M, Terazaki H, Tajiri T, Tanoue Y, Sun X, Okabe $\mathrm{H}$, Tanihara H: Amyloid deposition in ocular tissues of patients with familial amyloidotic polyne uropathy (FAP). Amyloid 2002;9:183-189.

18 Ciulla TA, Tolentino F, Morrow JF, Dryja TP: Vitreous amyloidosis in familial amyloidotic polyneuropathy. Report of a case with the Val30Met transthyretin mutation. Surv Ophthalmol 1995;40:197-206.

19 Salvador F, Mateo C, Alegre J, Reventos A, García-Arumi J, Corcostegui B: Vitreous amyloidosis without systemic or familial involvement. Int Ophthalmol 1993-1994;17:355-357.

20 Ferry AP, Lieberman TW: Bilateral amyloidosis of the vitreous body without systemic involvement. Arch Ophthalmol 1976;94:982-991.

-21 Ando E, Ando Y, Maruoka S, Sakai Y, Watanabe S, Yamashita R, Okumura R, Araki S: Ocular microangiopathy in familial amyloidotic polyneuropathy, type1. Graefes Arch Clin Exp Ophthalmol 1992;230:1-5.

22 Connors LH, Lim A, Prokaeva T, Roskens VA, Costello CE: Tabulation of human transthyretin variants, 2003. Amyloid 2003;10:160-184.

-23 Holmgren G, Hellman U, Lundgren HE, Sandgren O, Suhr OB: Impact of homozygosity for an amyloidogenic transthyretin mutation on phenotype and long term outcome. J Med Genet 2005;42:953-956.

-24 Koga T, Ando E, Hirata A, Fukushima M, Kimura A, Ando Y, Negi A, Tanihara H: Vitreous opacities and outcome of vitreous surgery in patients with familial amyloidotic polyneuropathy. Am J Ophthalmol 2003;135:188-193.

-25 Sandgren 0: Ocular amyloidosis, with special reference to the hereditary forms with vitreous involvement. Surv Ophthalmol 1995;40:173-196.

26 Beirão NM, Matos E, Beirão I, Costa PP, Torres P: Recurrence of vitreous amyloidosis and need of surgical reintervention in Portuguese patients with familial amyloidosis ATTR V30M. Retina 2011;31:1373-1377.

-27 Hitchings RA, Tripathi RC: Vitreous opacities in primary amyloid disease. A clinical, histochemical, and ultrastructural report. Br J Ophthalmol 1976;60:41-54.

-28 Martone RL, Herbert J, Dwork A, Schon EA: Transthyretin is synthesized in the mammalian eye. Biochem Biophys Res Commun 1988;151:905-912.

29 Kawaji T, Ando Y, Nakamura M, Yamamoto K, Ando E, Takano A, Inomata Y, Hirata A, Tanihara H: Transthyretin synthesis in rabbit ciliary pigment epithelium. Exp Eye Res 2005;81:306-312.

-30 Ando Y, Ando E, Tanaka Y, Yamashita T, Tashima K, Suga M, Uchino M, Negi A: De novo amyloid synthesis in ocular tissue in familial amyloidotic polyneuropathy after liver transplantation. Transplantation 1996;62:1037-1038.
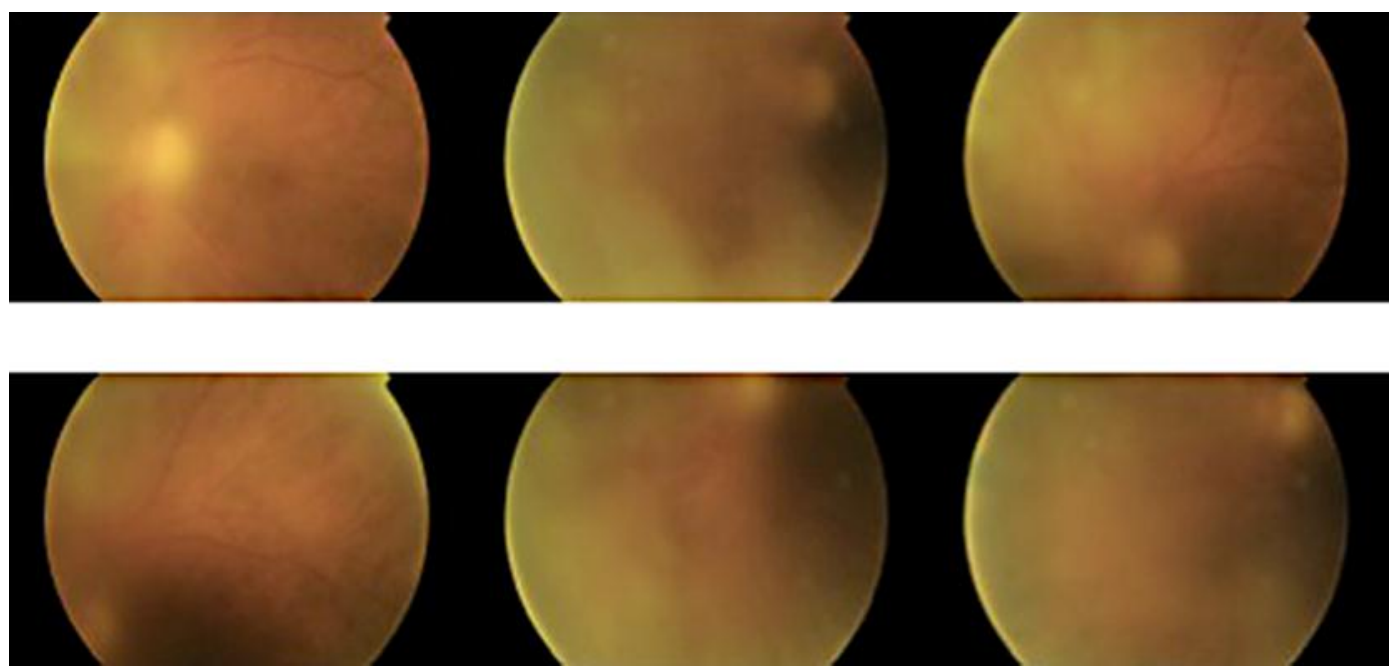

Fig. 1. Retinography of the left eye. 
Case Reports in

Ophthalmology
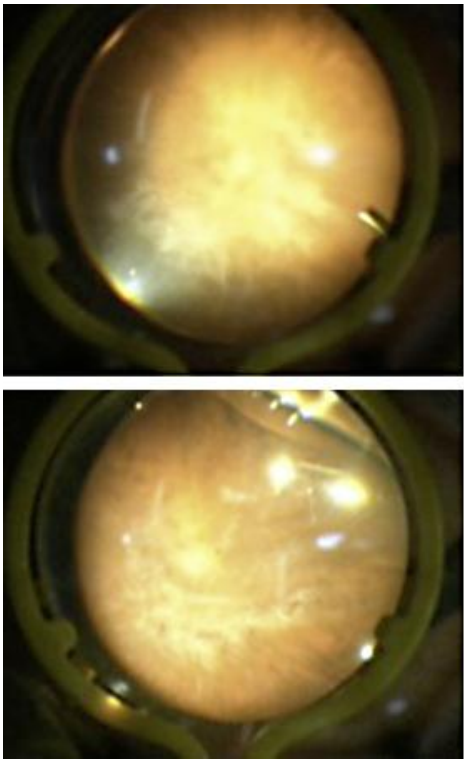

Fig. 2. Vitrectomy of the left eye.

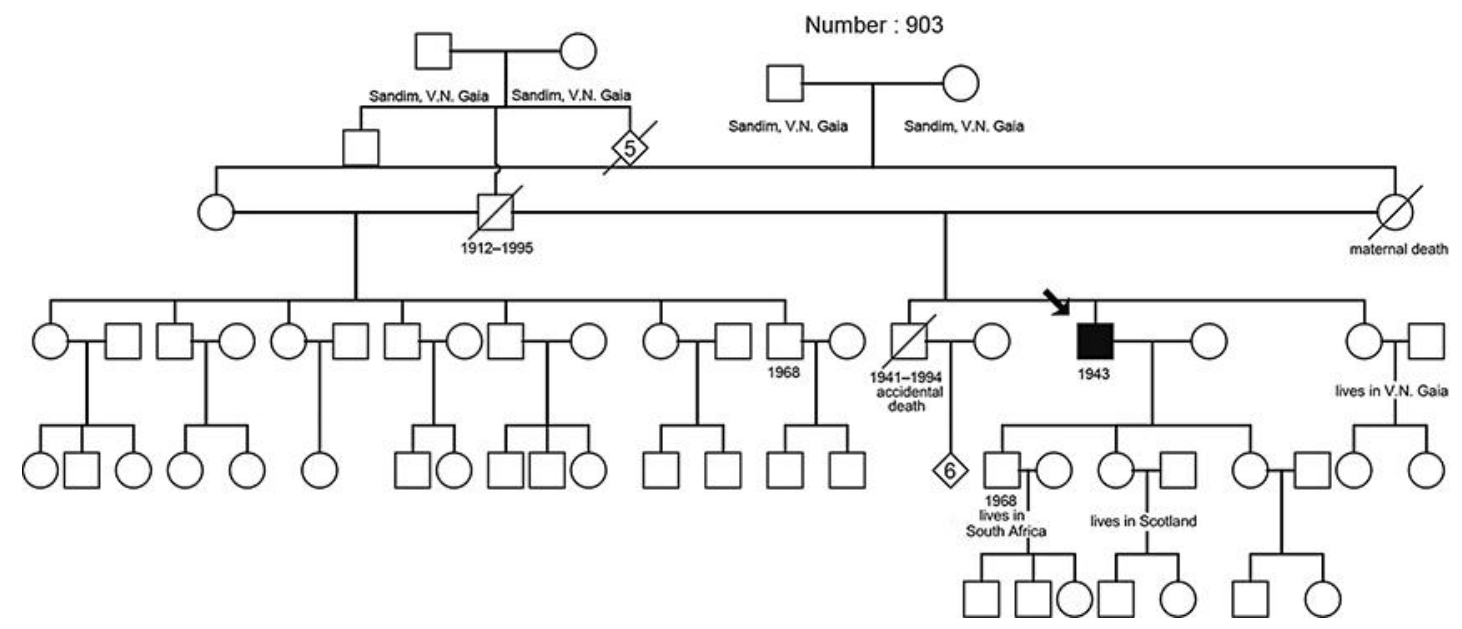

Fig. 3. Family tree.

Case Rep Ophthalmol 2014;5:92-97

DOI: $10.1159 / 000360790$

(c) 2014 S. Karger AG, Base

www.karger.com/cop

Seca et al.: Vitreous Amyloidosis as the Presenting Symptom of Familial Amyloid Polyneuropathy TTR Val30Met in a Portuguese Patient
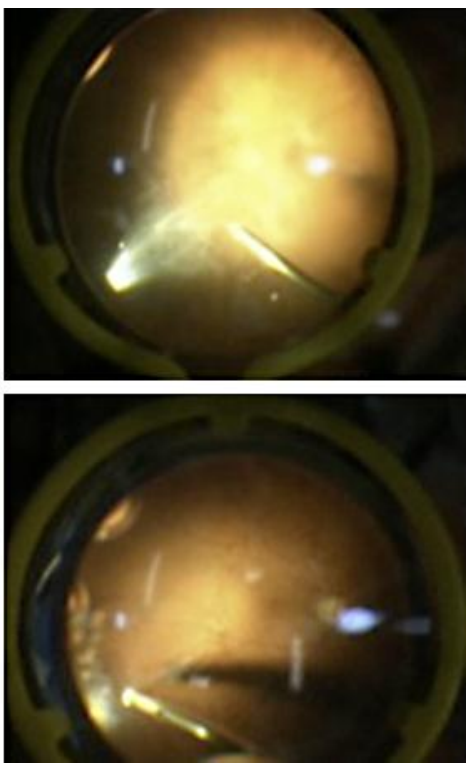